\title{
Influence of Welding on Dynamic Fracture Toughness of Strenx 700MC Steel
}

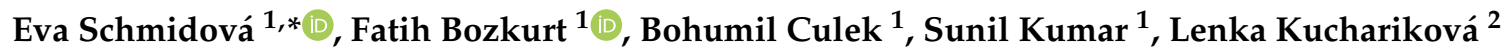 \\ and Milan Uhríčik ${ }^{2}$ \\ 1 Faculty of Transport Engineering, Department of Mechanic and Materials, University of Pardubice, \\ Studentská 95, 53210 Pardubice, Czech Republic; st43852@student.upce.cz (F.B.); \\ bohumil.culek@upce.cz (B.C.); sunilmr21@gmail.com (S.K.) \\ 2 Faculty of Mechanical Engineering, Department of Materials Engineering, University of Žilina, Univerzitná \\ 8215/1, 01026 Žilina, Slovakia; lenka.kucharikova@fstroj.uniza.sk (L.K.); milan.uhricik@fstroj.uniza.sk (M.U.) \\ * Correspondence: eva.schmidova@upce.cz; Tel.: +420-466-036-444
}

Received: 7 February 2019; Accepted: 26 April 2019; Published: 28 April 2019

check for updates

\begin{abstract}
Thermomechanically processed high-strength steels feature specific fracture behavior. One of the decisive criteria for their application is their stability against internal defects during impact loads, especially in connection with the welding. The work is focused on experimental analyses of the influence of welding on static and dynamic fracture toughness of Strenx 700MC steel. The fracture toughness was determined using the circumferentially notched round bar specimens during static loads and two dynamic load levels. To achieve a homogeneous zone for the requirements of fracture toughness tests, simulation of the welding influence was performed. Fractographic and metallographic analyses described a specific fracture behavior controlled by the internal structural heterogeneity. A limiting degradation process due to welding was identified by the microstructural analysis.
\end{abstract}

Keywords: dynamic fracture toughness; high strength steels; fracture behavior; welding influence; heat-affected zone; simulation of welding; heterogeneous carbide precipitation

\section{Introduction}

The use of high-strength steel in the construction of means of transport has grown over the years. The driving force is both technical and environmental, where passive safety requirements have brought about the development of ultra-high-strength steel based on specific processes of dynamic strengthening during the crash-strain rate [1,2]. Particularly for the application in means of transport, a variety of steels after thermomechanical treatment meet the increasing requirements for lightweight construction and therefore for an increased efficient loading capacity and lower fuel consumption [3-5].

One of the most effective processes to increase material resilience to a critical sudden fracture is to influence the natural crack propagation through microstructural heterogeneity. The thermomechanical treatment of steels with limited semi-product thickness leads to microstructural and mechanical heterogeneity, which can positively affect the fracture behavior of steel. The presented study is focused on the mentioned process using one of the prospective steels for lightweight constructions-Strenx 700MC. Strenx 700MC steel is characterized by the strain hardening and strain-rate hardening; the prospective restriction in the particular application can be a thermal softening effect after welding. The strength decrease caused by thermal impacts of specific technology is the subject of numerous studies [6-9]. The worst impact properties are commonly obtained in the coarse-grained zone near the fusion line $[10,11]$.

A frequent limitation for the wider use of this type of steel, such as in the railway vehicle chassis design, is the lack of data on induced material sensitivity changes due to internal defects during impact 
loads. During heating, fine carbides dissolve and re-form with the intensity depending on the cooling rate. The resulting fracture behavior in the weld joint critical zone is a question of the interaction of the change in the grain structure and specified phase changes, which can counteract the stability against the development of defects.

The fracture mode of the tested steel is driven by local heterogeneity. The extension of the plastic zone at the tip of a crack strictly depends on numerous variables, such as the yield stress, the crack length, the strain rate, and the thickness of the cracked component. In the case of significant toughness anisotropy, crack growth tends to be in the direction of a weaker zone and may not be in the direction of the initial crack even for mode-I loading [12,13]. Determination of fracture toughness is a way to quantify the crack sensitivity, especially in connection with the thermal effect after welding. The crack depth, section thickness, specimen size, crack geometry and loading configuration have a strong effect on fracture toughness measurements. In order to obtain conservative, constraint-independent fracture toughness measurements, all fracture test standards prescribe strict specimen geometry requirements [14-17]. Despite a tendency to reduce the thickness of construction components, their real toughness is driven by the overall design, including welding joints.

The main objective of the experimental analyses was to obtain information about the fracture behavior of this steel at precisely defined load parameters and also at the defined initial structural steel state. Various loading rates and the impact of structural degradation by welding were included in the analyses.

Presented work has also verified the possibility of using the non-standardized circumferential pre-cracked round bar test method (CCRB) [18-24] to assess fracture toughness under static and dynamic loading. Advantageously, the positive influence of the peripheral initiated fatigue crack on the fracture propagation was applied. This method made it possible to perform the comparative tests to quantify the two main examined effects_-dynamic load and structural degradation in the critical layer of welded Strenx 700MC steel.

\section{Materials and Methods}

\subsection{Experimental Material}

The Strenx 700MC steel used in this study belongs to the category of microalloyed high-strength steels widely used for trailers, containers, truck frame rails, dump truck cabs, etc. The mechanical properties of Strenx 700MC meet or exceed the requirements in EN 10149-2. Strenx 700MC is a hot-rolled structural steel with a minimum yield strength of $700 \mathrm{MPa}$, made for cold forming and intended for stronger and lighter structures.

This steel type is typical by a low carbon content, an increased content of manganese, a reduced sulphur content, and the addition of micro-alloyed elements (see Table 1). The sum of $\mathrm{Nb}, \mathrm{V}$, and $\mathrm{Ti}$ is maximal $0.22 \%$ of steel content, and together with thermomechanical processing results in grain refinement and increases the strength and toughness. As for the influential technical, manufacturing, economic, and environmental aspects, this steel has good prerequisites for use in railway transport to reduce weight and increase payload.

Table 1. Chemical composition (wt. \%) of the used steels.

\begin{tabular}{cccccccccccc}
\hline \multicolumn{2}{c}{ Used Steels/Standards } & $\mathbf{C}$ & $\mathbf{S i}$ & $\mathbf{M n}$ & $\mathbf{P}$ & $\mathbf{S}$ & $\mathbf{A l}_{\text {tot }}$ & $\mathbf{N b}$ & $\mathbf{V}$ & $\mathbf{T i}$ \\
\hline \multirow{2}{*}{ Strenx } & EN 10149-2 (max.) & 0.12 & 0.21 & 2.1 & 0.020 & 0.010 & 0.015 & 0.09 & 0.20 & 0.15 \\
700MC & Sample & 0.047 & 0.028 & 1.75 & 0.009 & 0.0026 & 0.041 & 0.061 & 0.016 & 0.091 \\
\hline \multirow{2}{*}{ S355NJ } & Standard (max.) & 0.23 & 0.05 & 1.60 & 0.05 & 0.05 & - & - & - & - \\
& Sample & 0.15 & 0.18 & 1.32 & 0.017 & 0.0056 & 0.035 & - & 0.0016 & 0.001 \\
\hline
\end{tabular}

Today's railway frames are primarily made of material with a yield strength of 235-355 MPa. For that reason, the S355NJ steel (see Table 1 for chemical composition) was used as a referential steel for the performed experimental analyses. The real mechanical properties may significantly vary 
depending on the rolling direction. The mechanical parameters of the analyzed steels in a longitudinal direction, i.e., the same as the direction of samples used for all performed analyses, are in Table 2.

Table 2. Static mechanical parameters of the used steels.

\begin{tabular}{ccc}
\hline Material & Yield Strength (MPa) & Tensile Strength (MPa) \\
\hline S355NJ & 516 & 550 \\
Strenx 700MC & 623 & 683 \\
\hline
\end{tabular}

\subsection{Methodology of Fracture Testing}

The Strenx 700MC steel is typical by significant structural heterogeneity, where the fracture response is controlled by local differences of plasticity. The structural state of material affects the usability of possible assessment methods, especially for dynamic fracture toughness assessments. One of the ways to evaluate the dynamic fracture toughness for steel plates of limited width is a measurement of fracture toughness at impact loading rates using pre-cracked Charpy-type test pieces. Testing single-edge bend specimens (SENB), fatigue pre-cracked and loaded in three-point bending, is introduced in the ISO 26843 [25] and ASTM E 1820 [26], standards, including the recommended shape, specimen dimensions, and fatigue pre-cracking requirements.

The pre-cracked Charpy-type test was employed to verify this methodology for the used steel with defined thickness. For the dynamic test, $10 \mathrm{~mm} \times 5 \mathrm{~mm} \times 55 \mathrm{~mm}$ samples were used with a chevron notch (according to EN ISO 12737), as shown in Figure 1. As shown below, the use of a 1-sided notched specimen has led to an unacceptable deflection of the crack face and false plasticity indication.

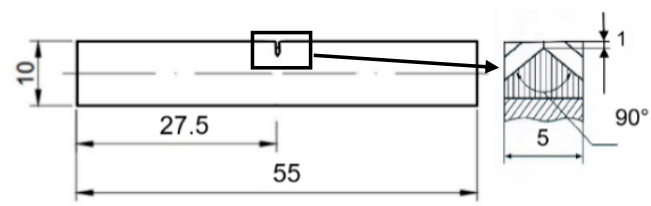

Figure 1. Chevron notched sample for dynamic fracture toughness testing (unit: $\mathrm{mm}$ ).

Therefore, we used the variant method to assess the material sensitivity against the development of cracks using the round specimens. This approach enables radial pre-cracking and uniaxial static and also dynamic loading, e.g., research of strain rate sensitivity up to the standard crash rate loading [13-16]. The circumferential pre-cracked round bar test method (CCRB) is based on round specimens fatigue pre-cracked at a defined notch and loaded in a uniaxial tensile test (at different loading rates) until failure. The specimens with V-type notches with notch angles of $60^{\circ}$ and $1 \mathrm{~mm}$ radial depth, mean notch radius 0.225 , and with the dimensions displayed in Figure 2 were used in the performed analyses. The specimen was prepared from steel plates parallel to rolling.

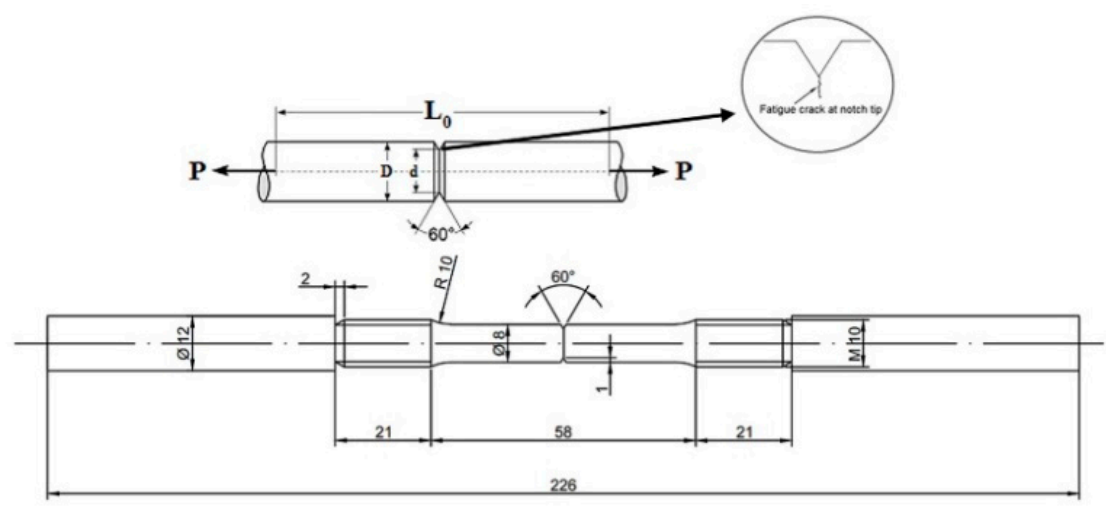

Figure 2. Round specimen for dynamic fracture toughness testing (unit: $\mathrm{mm}$ ). 
An R.R. Moore four-point rotating bending fatigue-loading machine (MEZIM, Moscow, Russian) was used for specimen pre-cracking as shown in Figure 3 and the crack propagated radially towards the center of the specimens. The specimens were subjected to cyclic tensile-compressive loads $\left(R_{\text {stress }}=-1\right)$. The chosen bending loading $(\mathrm{M})$ had to respond to the maximum stress intensity factor $K_{\max }$, which should not exceed $60 \%$ of the minimum expected $K_{\text {IC }}$ fracture toughness of the tested material.

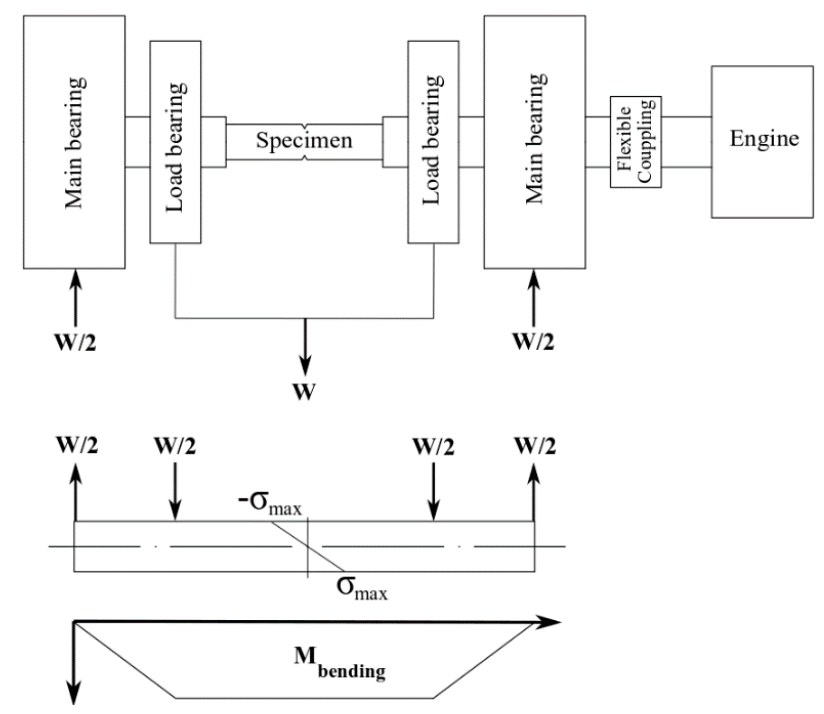

Figure 3. R. R. Moore four-point fatigue testing machine.

The pre-cracking process was controlled by a JK-1 Crack Depth Meter device (JaKM, Prague, Czech Republic), based on the measurement of the electrical resistance at the notched area. Particular resistance levels, according to the surface and initial notch geometry conditions of each sample, were measured during individual calibration processes for all samples. When a fatigue crack was detected, the specimen was ready for the static or dynamic tensile test.

For mode-I loading conditions, the pre-cracked specimen was loaded under both static and dynamic tension conditions. A crosshead displacement rate of $0.5 \mathrm{~mm} / \mathrm{min}$ until failure was used for the evaluation of the static fracture response. In order to investigate the effect of the loading rate on the dynamic fracture toughness of the materials, the impact tensile tests were conducted at two different impact velocities, namely 3.48 and $5.23 \mathrm{~m} / \mathrm{s}$. In the present study, a Zwick/Roell RKP 450 connected to a PC with the testXpert testing software (TestXpert II Master, Zwick\&Co.KG, Ulm, Germany, 2016) was chosen to conduct the instrumented impact tensile tests. The force and crosshead displacement were also recorded during the static and dynamic tensile tests. All tests were performed at room temperature. A minimum of three specimens of the material was tested under the same conditions for fracture toughness calculation. The maximum loads reached by each specimen were specified.

After completion of the uniaxial tests, the fracture surface of the specimen was investigated, and specified dimensions were measured with a stereomicroscope as shown in Figure 4 . To calculate fracture toughness, defined dimensions were machined notch depth $\left(a_{\mathrm{m}}\right.$-region $\left.\mathrm{A}\right)$ and length of fatigue pre-crack $\left(a_{\mathrm{f}}\right.$-region B). Stable vs. unstable fracture modes were distinguished inside the final fracture range (region $C$ ) in the case of different fracture modes action.

For determination of the fracture toughness of the material, the effective diameter $\left(d_{\mathrm{eff}}\right)$ was stated:

$$
d_{\mathrm{eff}}=D-2\left(a_{\mathrm{m}}+a_{\mathrm{f}}\right)
$$

Depending on the effective diameter $\left(d_{\text {eff }}\right)$, unnotched section diameter $(D)$ and maximum reached force during the impact tensile test, static fracture toughness $\left(K_{\mathrm{IC}}\right)$ and dynamic fracture toughness $\left(K_{\mathrm{Id}}\right)$ were calculated as follows [24]: 


$$
\begin{aligned}
K_{\mathrm{IC}} & =\frac{P_{\mathrm{f}}}{D^{3 / 2}}\left[1.72 \frac{D}{d_{\mathrm{eff}}}-1.27\right] \\
K_{\mathrm{Id}} & =\frac{P_{\mathrm{dmax}}}{D^{3 / 2}}\left[1.72 \frac{D}{\mathrm{~d}_{\mathrm{eff}}}-1.27\right]
\end{aligned}
$$

where $P_{\mathrm{f}}$ and $P_{\mathrm{dmax}}$ were the maximum static and dynamic fracture load, respectively. The valid range of Equations (2) and (3) is $0.46<\left(d_{\mathrm{eff}} / D\right)<0.86$ [24].

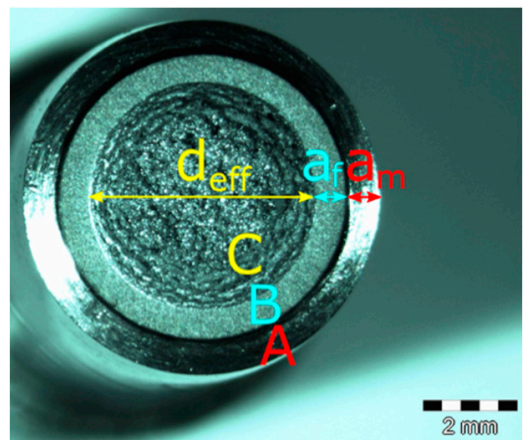

Figure 4. Defined fracture regions for fracture toughness determination.

\subsection{Experimental Welding and Simulation of Impact of Welding on Samples for Fracture Tests}

The above-mentioned approach, using round-bar specimens, was also used to provide a more detailed description and understanding of the degradation caused by welding. The welding effect evaluation was performed with the support of experimental welding and subsequent simulation of the maximal degradation effect in the area of fracture propagation.

Steel plates with dimensions of $120 \mathrm{~mm} \times 300 \mathrm{~mm} \times 10 \mathrm{~mm}$ and V-type grooves were prepared for the resistance welding process, as shown in Figure 5. The Kempact 253R welding equipment was used for MAG welding ( $\mathrm{CO}_{2}$ and Ar shielding gases), with three welding passes using Böhler UNION NiMoCr $\varnothing 1 \mathrm{~mm}$ filler wire (Table 3). The heat input for each welding pass was between 1.1 and $1.5 \mathrm{KJ} / \mathrm{mm}$; no heat treatment process such as stress relief annealing was carried out after or before the welding process.

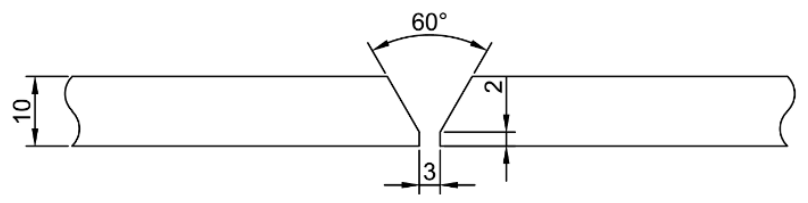

Figure 5. Details of V type configuration and dimensions of Strenx 700MC plate (unit: $\mathrm{mm}$ ).

Table 3. Chemical composition (wt. \%) of filler wire Böhler UNION NiMoCr Ø1.

\begin{tabular}{cccccc}
\hline $\mathbf{C}$ & $\mathbf{S i}$ & $\mathbf{M n}$ & $\mathbf{C r}$ & $\mathbf{M o}$ & $\mathbf{N i}$ \\
\hline 0.08 & 0.60 & 1.70 & 0.20 & 0.50 & 1.50 \\
\hline
\end{tabular}

The real weld joint evaluation was used to identify the heat affected zone (HAZ) sublayer critical to the initial strength of the steel. The hardness measurement and microstructural evaluation served as parameters for identifying the critical degradation effects of the used experimental welding technology. The minimum hardness value of the heat affected zone showed a critical temperature for the next simulation of a critical degradation process.

The simulation of welding heat effect on the Strenx 700MC steel was carried out for two reasons. The first reason was the potential presence of microscopic defects that cannot be totally excluded and that affect the results of any weld joint tests. The purpose of the performed research was not to verify 
the technology itself, but to examine the degradation effect on the material in question, its substance and its influence on dynamic fracture behavior. Secondly, the welding effect simulation allows the creation of a geometrically optimized HAZ for fracture toughness analysis. As an accurate orientation of the developing crack to the zone with the maximum degradation impact of the welding is necessary for these tests, this area must be structurally homogeneous throughout the tested cross section. The simulation, by the localized critical heating, allows the controlled preparation of much wider critical HAZ sublayers with typical heat levels and corresponding microstructural effects. The used approach was chosen to suppress the natural structural gradient in the HAZ, which usually results in scattering results. The critical thermal effect was simulated to create the critical HAZ sublayer located in the crack propagation plane and, thereby, to accurately evaluate the fracture toughness after welding.

A welding simulation was performed using the WTU 315-3 welding equipment without the filler material. The specimens made for the fracture analyses were heated by an electric arc over copper rings. The critical temperature and thus the limit degradation effect were induced in the notched part of the samples. During the welding simulation process, the temperature was recorded by an Omega HH309A four-channel data logger thermometer over time. Time and temperature records were used to reproduce the heating regime used. The structural analysis and hardness measurement were performed to validate the simulation process by means of comparison with the real critical HAZ sublayer. The specimens before and after the welding simulation process and typical induced temperature gradient are shown in Figure $6 a, b$, respectively.

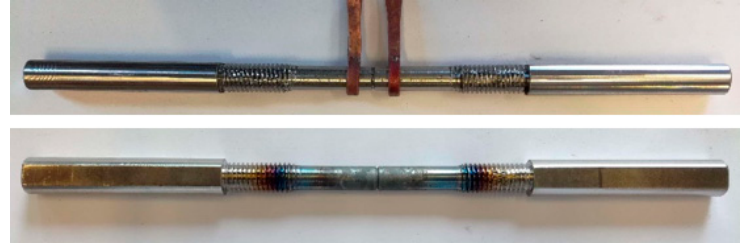

(a)

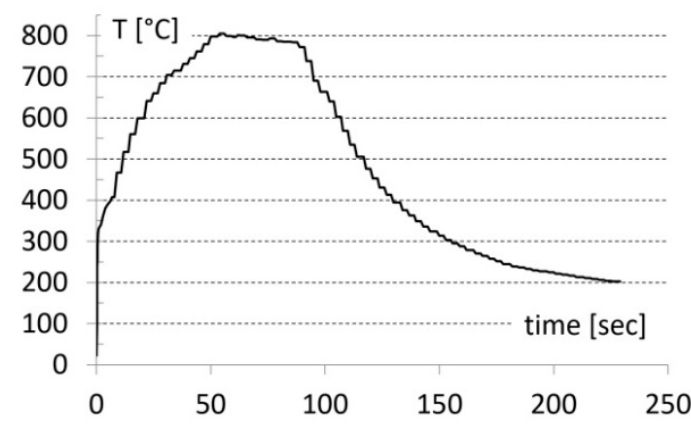

(b)

Figure 6. Simulation of the critical influence of welding: (a) Samples before/after heating; (b) induced temperature gradient.

\section{Results}

\subsection{Verification Analysis of Welding Simulation}

As a first step, the complex material analyses of experimentally welded Strenx 700MC steel were performed to identify the critical sublayer of HAZ in terms of structural degradation and to describe the involved degradation process. The local differences in hardness have shown the weakest area of the welding joint and the most intensive degradation effect of welding in the used high-strength steel. Identification of the most softened sublayer provided information about the critical temperature level for the design of the weld thermal influence simulation.

The Vickers hardness measurement of the welded specimen (according to EN ISO 6507-1) was conducted perpendicularly to the weld joint axis, on the HV1 scale, with a $0.2 \mathrm{~mm}$ interval-see Figure 7. The hardness measurement indicated the lowest values in the sublayer of the outer part of the grain refinement zone (236 HV1). 


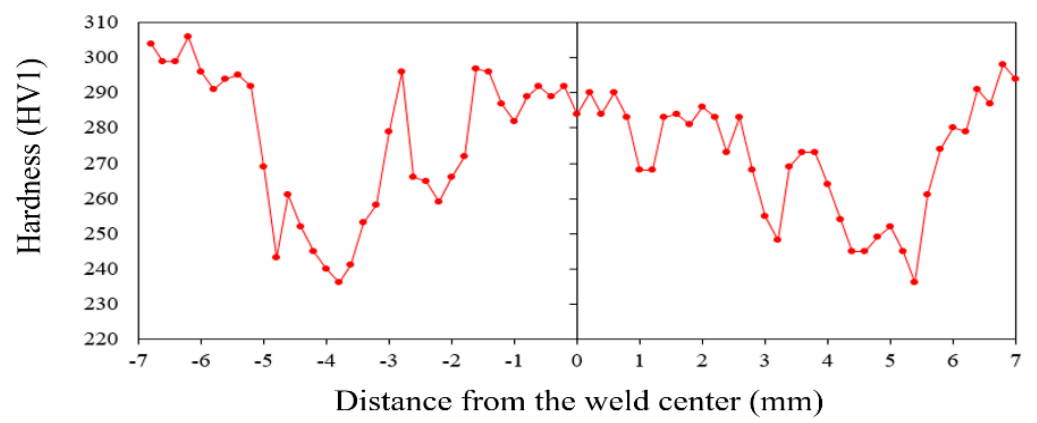

Figure 7. HV1 hardness vs. distance from weld center for welded Strenx 700MC specimen.

A simulation of the degradation process was designed based on the analyses of experimental welding process influences. During the thermal cycle simulation, the specimen, with geometry for static or dynamic uniaxial tests, was heated to a maximum temperature of $800{ }^{\circ} \mathrm{C}$ and held at this temperature for $5 \mathrm{~s}$; the temperature was recorded as a function of time. For validation of the used simulation, the thermal cycle influence was evaluated by the metallography analyses and hardness measurement. The samples were extracted from the longitudinal axis of the circumferentially round bar specimen of the Strenx 700MC steel and prepared by a standard metallographic preparation process. Stable hardness values at the notch tip presented very important results in terms of material homogeneity in the fracture plane, i.e., they prove the suitable conditions for the fracture resistance evaluation. The hardness values varied from 216 to $233 \mathrm{HV} 1$, and the mean value was approximately 225 HV1. As mentioned above, the main aim was to approach the lowest hardness level (236 HV1), which was induced in the experimental welding sample of Strenx 700MC. In this way, the suitability of the simulation used to assess the degradation process due to welding was verified.

\subsection{Metallography Evaluation of Related Structural Effects}

The microstructure of uninfluenced Strenx700MC steel consists of a fine-grained polygonal ferrite with a limited amount of pearlite. Outstanding strength and impact toughness are a result of the fine-grained microstructure in combination with thermomechanical rolling in a hot strip mill. The overall view of the experimental HAZ weld is presented in Figure 8. Typical microstructural effects of the applied welding technology, compared to the simulation effect, are documented in Figure 9.

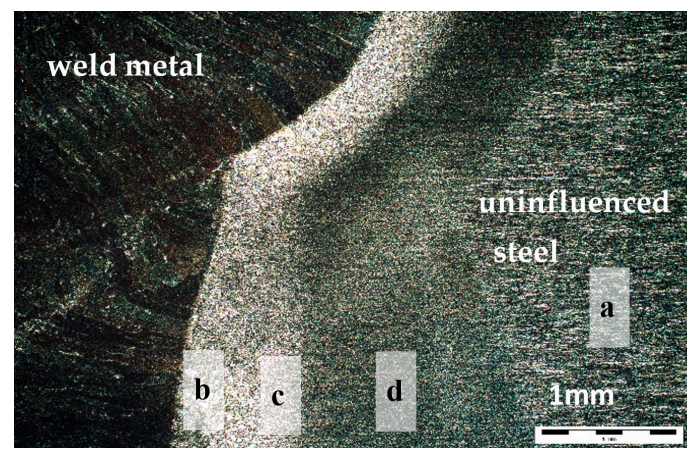

Figure 8. Macroscopic view of the HAZ; the positions of detailed views in Figure 9.

The ferritic structure of the uninfluenced test steel has shown a partial acicular morphology along with the distribution of very fine carbides (Figure 9a), which contributes to increased strength. Re-austenitisation caused a typical grain coarsening in the so-called superheated welding area adjacent to the fusion zone (Figure 9b). Grain refinement was observed in a substantial part of the HAZ; in addition to the influence on the grain size, the heat input led to the carbide re-precipitation. Significant distribution of relatively coarsened carbides (up to $1 \mu \mathrm{m}$ thick) was found in the band 
immediately above the austenitisation temperature (Figure 9c), contrary to the partially austenitization zone (Figure 9d). Much finer and less globularised carbides were formed in the grain-coarsened zone.
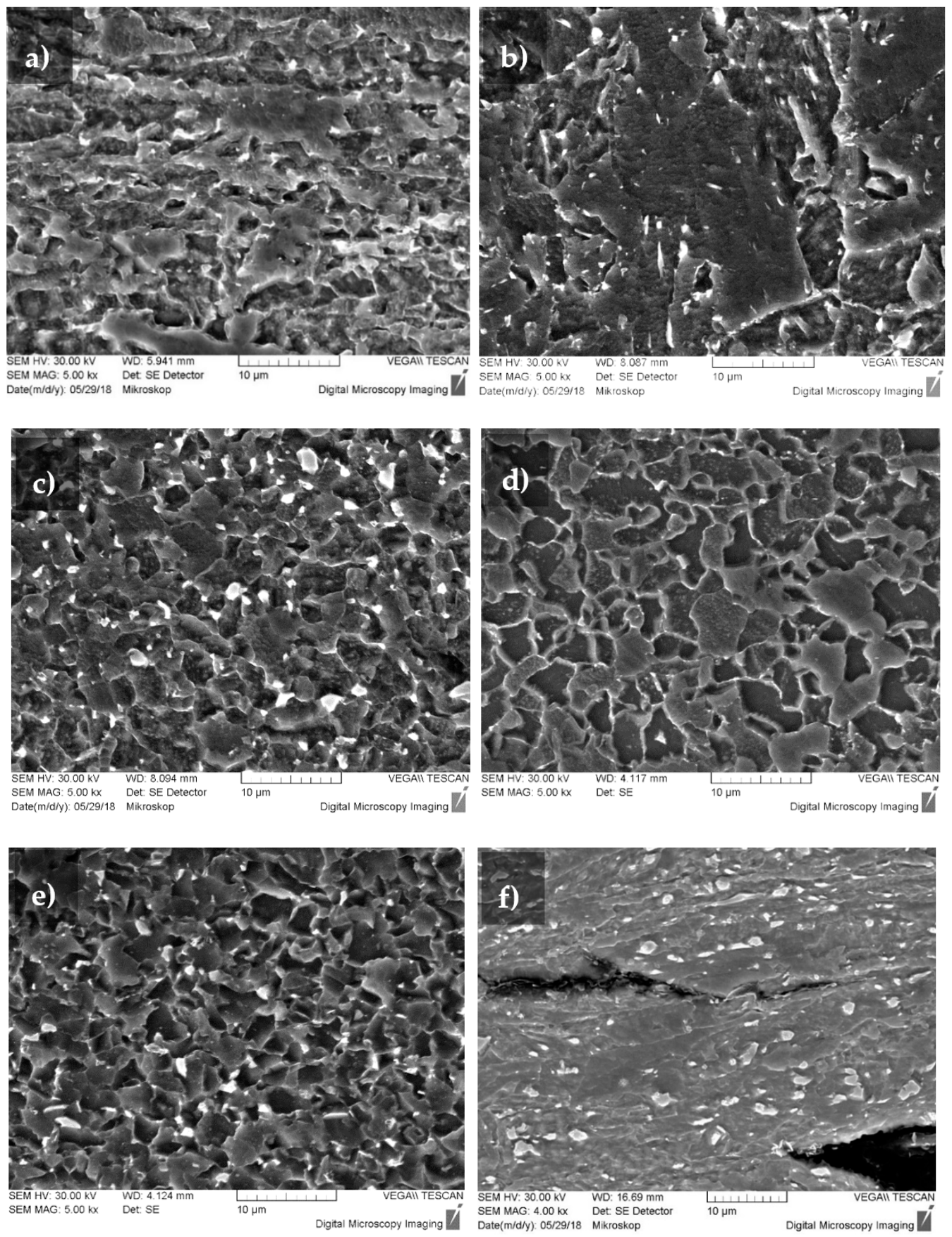

Figure 9. Strenx 700MC structural changes after used welding technology and simulation: (a) Uninfluenced steel; (b) grain coarsened zone along the fusion zone; (c) carbides coarsening in the grain refined zone; (d) partially austenitization zone; (e) microstructure obtained by simulation;

(f) microstructure obtained by simulation near the fracture.

After completion of the welding influence simulation, a sample for the metallographic examination was prepared from the circumferential notched round bar specimen. Comparative structural analyses were conducted directly in the area of the notch tip, i.e., in the area of crack propagation within the fracture toughness examination. The carbide reprecipitation process was found to be the most effective degradation process by the metallography evaluation of the real welding influence. Due to that, the 
comparison of dissolution and reprecipitation of carbides was also an important validation effect of the performed simulation process. As shown in Figure 9e, coarsening of the primary carbides was induced by the simulation process. This observation confirms accordance with the critical structural influence of real welding processes. The initiation of microcracks along the coarsened carbides during mechanical testing was also visible (Figure 9f).

\subsection{Fracture Response Evaluation}

Chevron-notched sample testing led to unacceptable fracture responses in all tested positions. The plane of the fracture deflected immediately as the tip of the crack reached the carbide row, so the real distribution of carbides has de facto driven the following fracture plane and thus influenced all the measured results, namely the maximal force and total energy consumption. Figure 10a presents the influence of the position of crack deflection on the fracture resistance of the Strenx 700MC steel. Furthermore, the tendency to ductile fracture is evident from the detail in Figure 10b, i.e., plane deformation condition, was not achieved.

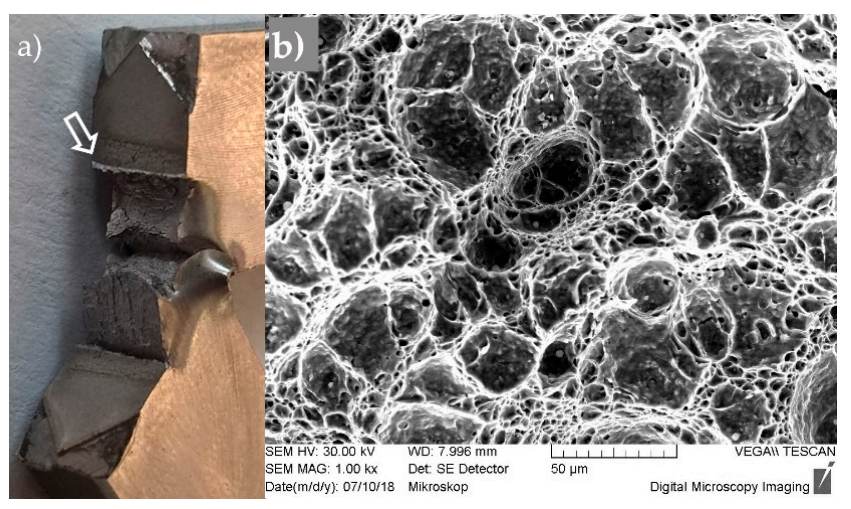

Figure 10. Fractured chevron notched samples: (a) Crack deflection due to carbide precipitation;

(b) ductile fracture mode.

The results of static versus dynamic fracture toughness of the parent material, determined using the CCRB method, are listed in Table 4 compared to the S355NJ steel. Dynamic values obtained at the maximal loading rate are significantly higher compared to the static values, so a strengthening process has been involved. It points to the presence of an effective plastic zone on the tip of the moving fracture, which enables the dislocation hardening process. An increased scattering of dynamic strength and fracture toughness values was obtained at the maximal loading rate. The heat input of simulated welding caused significant change of static and also dynamic fracture responses; the fracture toughness values are listed in Table 5.

An uneven circumference fatigue crack caused by a stripe of carbide precipitation was typical for all loading conditions. The lamellar final fracture morphology (Figure 11) was observed and evaluated in both the macro and microscale to assess an increased loading rate influence on fracture behaviour. Figure $11 \mathrm{a}$ compared to Figure $11 \mathrm{~b}$ presents the macroscopic appearance of the fracture surface after its static compared to dynamic loads. In both cases, the influence of the lamellar precipitation of very fine carbides is dominant, with the higher occurrence of secondary cracks typical of dynamic loading, which partly led to the fracture relief refinement. The simulation of the critical welding influence has led to the fundamental change in the morphology of the fracture surface. The lamellar character of the fracture was completely suppressed (Figure 11c), which corresponds to the observed structural effect, i.e., carbide reprecipitation. It also proves the complete removal of dislocation reinforcement after thermomechanical treatment. 

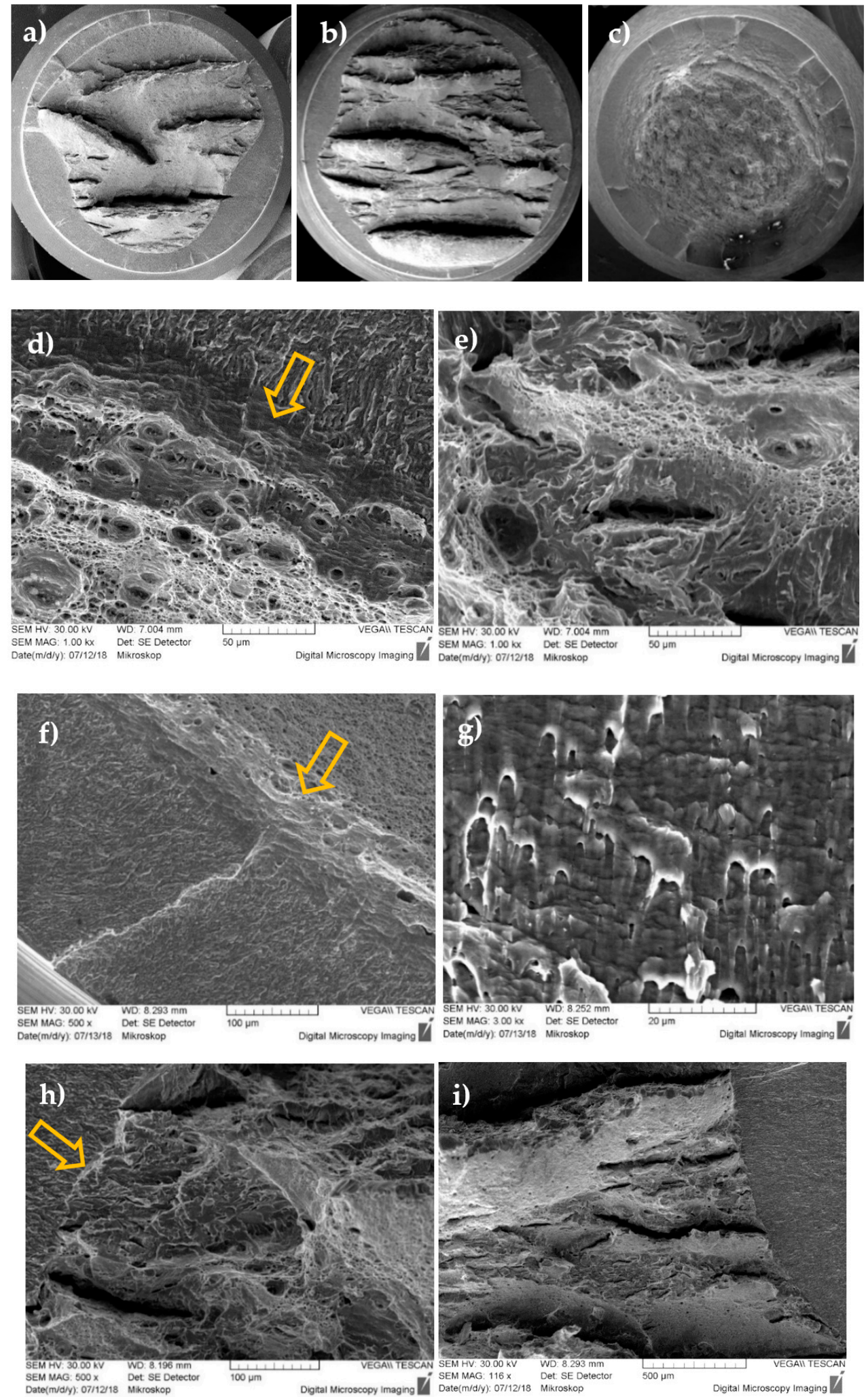

Figure 11. Fracture morphology of tested samples, (a) static-uninfluenced steel; (b) dynamicuninfluenced steel; (c) dynamic-HAZ; (d,e) static loaded uninfluenced steel; (f,g) uninfluenced steel loaded by impact velocity $3.48 \mathrm{~m} / \mathrm{s}$; (h,i) uninfluenced steel loaded by impact velocity $5.23 \mathrm{~m} / \mathrm{s}$. 
Table 4. Fracture response results of the Strenx 700MC at different loading rate-parent material.

\begin{tabular}{|c|c|c|c|c|c|c|c|c|}
\hline $\begin{array}{c}\text { Loading } \\
\text { Rate }\end{array}$ & $\begin{array}{c}\text { Sample } \\
\text { No. }\end{array}$ & $F_{\max }(\mathrm{N})$ & $D(\mathrm{~mm})$ & $a_{\mathrm{m}}(\mathrm{mm})$ & $a_{\mathrm{f}}(\mathrm{mm})$ & $\begin{array}{c}d_{\text {eff }} \\
(\mathrm{mm})\end{array}$ & $d_{\mathrm{eff}} / D$ & $\begin{array}{c}K_{\mathrm{I}} \\
\left(\mathrm{MPa} \cdot \mathrm{m}^{1 / 2}\right)\end{array}$ \\
\hline \multirow{5}{*}{$\begin{array}{c}\text { Static } \\
0.02 \mathrm{~m} / \mathrm{s}\end{array}$} & S1 & 28,744 & 7.7 & 0.7 & 0.64 & 5.02 & 0.65 & 58.2 \\
\hline & $\mathrm{S} 2$ & 31,953 & 7.65 & 0.695 & 0.47 & 5.32 & 0.70 & 57.5 \\
\hline & S3 & 32,243 & 7.61 & 0.69 & 0.38 & 5.47 & 0.72 & 54.5 \\
\hline & \multicolumn{7}{|c|}{ Average value } & 57 \\
\hline & \multicolumn{7}{|c|}{ Average value-S355NJ } & 45 \\
\hline \multirow{5}{*}{$\begin{array}{l}\text { Dynamic } \\
3.48 \mathrm{~m} / \mathrm{s}\end{array}$} & D-01 & 43,676 & 7.62 & 0.69 & 0.2 & 5.84 & 0.77 & 64 \\
\hline & D-02 & 41,164 & 8.11 & 0.75 & 0.42 & 5.77 & 0.71 & 64.7 \\
\hline & D-03 & 44,534 & 8.11 & 0.73 & 0.25 & 6.15 & 0.76 & 60.9 \\
\hline & \multicolumn{7}{|c|}{ Average value } & 63 \\
\hline & \multicolumn{7}{|c|}{ Average value-S355NJ } & 67 \\
\hline \multirow{7}{*}{$\begin{array}{l}\text { Dynamic } \\
5.23 \mathrm{~m} / \mathrm{s}\end{array}$} & D-1 & 41,484 & 7.59 & 0.695 & 0.3216 & 5.56 & 0.73 & 67.7 \\
\hline & D-2 & 40,534 & 7.78 & 0.66 & 0.38 & 57 & 0.73 & 63.7 \\
\hline & D-3 & 43,833 & 6.95 & 0.535 & 0.211 & 5.46 & 0.79 & 69.6 \\
\hline & D-4 & 38,764 & 7.84 & 0.725 & 0.4865 & 5.42 & 0.69 & 68.1 \\
\hline & D-5 & 43,510 & 7.8 & 0.72 & 0.49 & 5.38 & 0.69 & 77.3 \\
\hline & \multicolumn{7}{|c|}{ Average value } & 69 \\
\hline & \multicolumn{7}{|c|}{ Average value-S355NJ } & 69 \\
\hline
\end{tabular}

Table 5. Strenx fracture response at different loading rate-simulated heat affected zone (HAZ).

\begin{tabular}{|c|c|c|c|c|c|c|c|c|c|}
\hline $\begin{array}{l}\text { Loading } \\
\text { Rate }\end{array}$ & $\begin{array}{c}\text { Sample } \\
\text { No. }\end{array}$ & $\begin{array}{c}F_{\max } \\
(\mathrm{N})\end{array}$ & $D(\mathrm{~mm})$ & $\begin{array}{c}a_{\mathrm{m}} \\
(\mathrm{mm})\end{array}$ & $a_{\mathrm{f}}(\mathrm{mm})$ & $\begin{array}{c}d_{\text {eff }} \\
(\mathrm{mm})\end{array}$ & $\begin{array}{c}K_{\mathrm{I}} \\
\left({\left.\mathrm{MPa} \cdot \mathrm{m}^{1 / 2}\right)}{ }^{1 / 2}\right.\end{array}$ & $d_{\mathrm{eff}} / D$ & $\begin{array}{l}\text { UTS } \\
\text { (MPa) }\end{array}$ \\
\hline \multirow{4}{*}{$\begin{array}{c}\text { Static } \\
0.02 \mathrm{~m} / \mathrm{s}\end{array}$} & WS-01 & 34,183 & 7.67 & 0.735 & 0.21 & 5.78 & 51.5 & 0.75 & 1303 \\
\hline & WS-02 & 24,784 & 6.98 & 0.74 & 0.35 & 4.8 & 52.3 & 0.69 & 1370 \\
\hline & WS-03 & 24,972 & 7.26 & 0.73 & 0.43 & 4.94 & 50.8 & 0.68 & 1303 \\
\hline & \multicolumn{6}{|c|}{ Average value } & 51.5 & 0.70 & 1325 \\
\hline \multirow{4}{*}{$\begin{array}{l}\text { Dynamic } \\
5.23 \mathrm{~m} / \mathrm{s}\end{array}$} & DWS-01 & 36,057 & 7.22 & 0.83 & 0.45 & 4.66 & 82 & 0.65 & 2114 \\
\hline & DWS-02 & 22,769 & 7.74 & 0.805 & 1.68 & 2.77 & 118.2 & 0.36 & 3778 \\
\hline & DWS-03 & 32,839 & 7.2 & 0.575 & 0.67 & 4.71 & 73.1 & 0.65 & 1885 \\
\hline & \multicolumn{6}{|c|}{ Average value } & 91.1 & 0.55 & 2592 \\
\hline
\end{tabular}

Our microscopic images document the effect of various load rates, i.e., deformation, on the mechanism of crack development in the thermally unaffected steel. The fracture mode in the initial phase of destruction, i.e., at the interphase of the fatigue fracture, was decisive for the further propagation of fractures and, thereby, for the total energy consumption. In the case of static loads (Figure 11d,e), we documented the onset of the ductile fracture, as determined over the entire fatigue crack circumference. When increasing the load speed to $3.48 \mathrm{~m} / \mathrm{s}$, a change in the orientation of microscopic shear bridges was observed. This effect may be attributed to the reduced opening of the V-notch prior to the crack development due to the increased load rate. Again, a ductile fracture mechanism was identified around the entire fatigue crack circumference. We have observed the quasi-cleavage fracture mode (Figure $11 \mathrm{~h}, \mathrm{i})$ at the maximum tested load rate $(5.23 \mathrm{~m} / \mathrm{s}$ ) on the fatigue crack face. The area of a ductile fracture mode, corresponding to the stable crack propagation, reached a decreasing area with increasing loading rate. The transition to a final unstable fracture was more affected by the carbide phase precipitation.

\section{Discussion}

Experimental welding revealed the substantial microstructural changes due to the applied metal active gas welding method. The hardness measurement indicated the lowest value in the sublayer at 
the rim of the grain refinement zone towards a lowered temperature (236 HV1). This result seemed to contradict the generally known grain refining effect. Based on the detailed microstructure evaluation, it could be concluded that it was a result of a partial austenitisation process, together with the loss of both primary-strengthening processes-dislocation hardening and precipitation hardening. The latter process was more effective, hence the reprecipitation of carbides leading to a substantial decrease in hardness. The minimal hardness level was an important parameter for the performed temperature cycle simulation (for the chosen maximal temperature). The region of grain coarsening was very narrow.

Microadditives of titanium, aluminium, and vanadium in this type of microalloyed steel strongly influenced the grain growth, recrystallization of austenite, and phase transformation as well as morphology of the transformed products. The most common effect of grain coarsening, i.e., the decreasing of hardness, was overcome by the partial transformation to acicular ferrite and bainite. The presence of nitrogen carbides, revealed in the HAZ by chemical microanalysis, indicated that there are sufficient levels of titanium needed to bind to free nitrogen, which is related to reduced aging processes, in the investigated steel.

\subsection{Fracture Behaviour under Welding Influence, Specific Conditions for Methodology of Fracture Toughness Evaluation}

The standardized pre-cracked Charpy-type test according to ISO 26843-2015 was used in the first step of testing. The distinctive row of carbide precipitation in the Strenx 700MC steel led to crack deflection, and de facto thereby caused the evaluation of the tests to be impossible. So the first step of experimental analyses underlined the need for non-standard tests. Uniaxial tests using round bar pre-cracked samples allowed the comparative static and dynamic fracture behaviour evaluation. Two main points-the effect of carbide reprecipitation and the sensitivity of steel to the strain rate-were found to be crucial parameters for the prospective application. Fracture toughness values, determined at the dynamic loading of up to $5.23 \mathrm{~m} / \mathrm{s}$, differ from values measured at quasi-static loading rates. Principally, it applies (and it is reported, e.g., in ISO 26843), that an increase in loading rate causes a decrease in fracture toughness when tests are performed in brittle or ductile-to-brittle fracture regimes; an increase in fracture toughness is observed in the fully ductile regime.

This generally acknowledged relation has been confirmed. The strengthening of the parent Strenx $700 \mathrm{MC}$ steel and the simulated critical sublayer of HAZ ratios under different loading rates is displayed in Figure 12. A substantial increase in sensitivity to the rate of loading was observed in HAZ. This can be explained by the reprecipitation of carbides; microstructure homogenization led to a more intensive dislocation hardening effect.

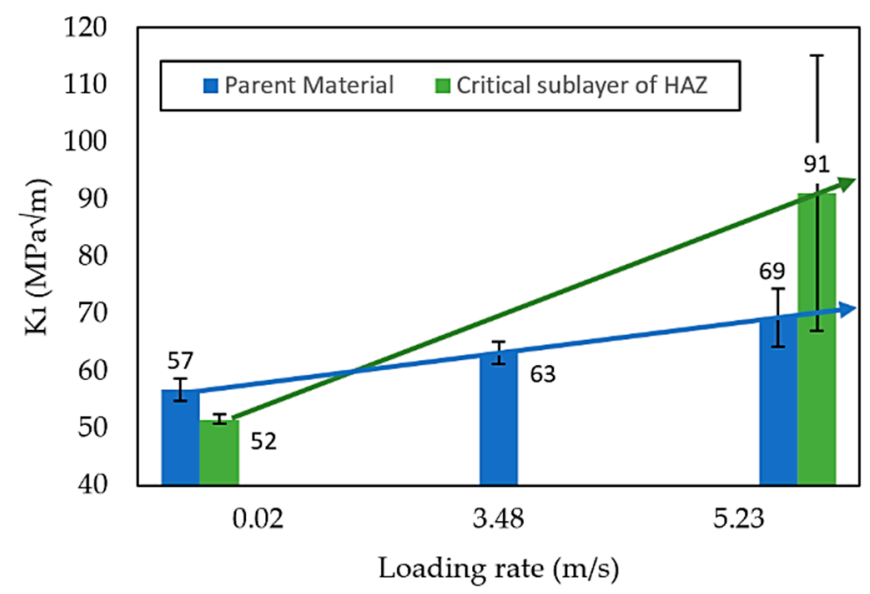

Figure 12. Fracture toughness of Strenx $700 \mathrm{MC}$ at different loading rate. 


\subsection{Effect of Structural Heterogenity}

The observed fracture response revealed significant influence on the primary structural heterogeneity of the Strenx 700MC steel. Lamellar-like tearing was observed in the uninfluenced area; hence the obtained values of energy were over-valuated due to the branching crack propagation. Complex fracture patterns appeared in all tested samples. The simulation of the welding degradation effect caused substantial changes in the fracture response. A slight decrease in fracture toughness at the static loading was observed together with more intensive dynamic strengthening. This can be explained by the induced contradictional structural effects in the HAZ-carbide reprecipitation as a crucial process towards strength impairment versus microstructural homogenization (by suppressing the row of carbide distribution) leading to increased susceptibility to deformation hardening. The performed experimental analysis of the static and impact crack behavior of simulated welded joints showed the real level of degradation caused by welding. The homogenization effect in the HAZ is capable of suppressing the primary strip-like carbide precipitation.

The fracture behavior of the Strenx 700MC steel in the particular fracture stages is reflected in the force-displacement diagrams. Representative records at different loading rates of the uninfluenced steel are displayed in Figure 13. A substantially different displacement of the final fracture presents the above-discussed effect of crack deflection due to the lamellar carbide precipitation. The generally acknowledged approach to fracture toughness evaluation using round-notched samples does not reflect the significant energy consumption differences in the case of similar maximal force to fracture. In this specific case, however, there is no continuous development of macroplastic deformation. The decisive factor is that, as opposed to the fracture toughness test using the Charpy-type samples, the evaluation regime used here leads to a magistrate crack in the final plane and thus de facto allows for evaluation.

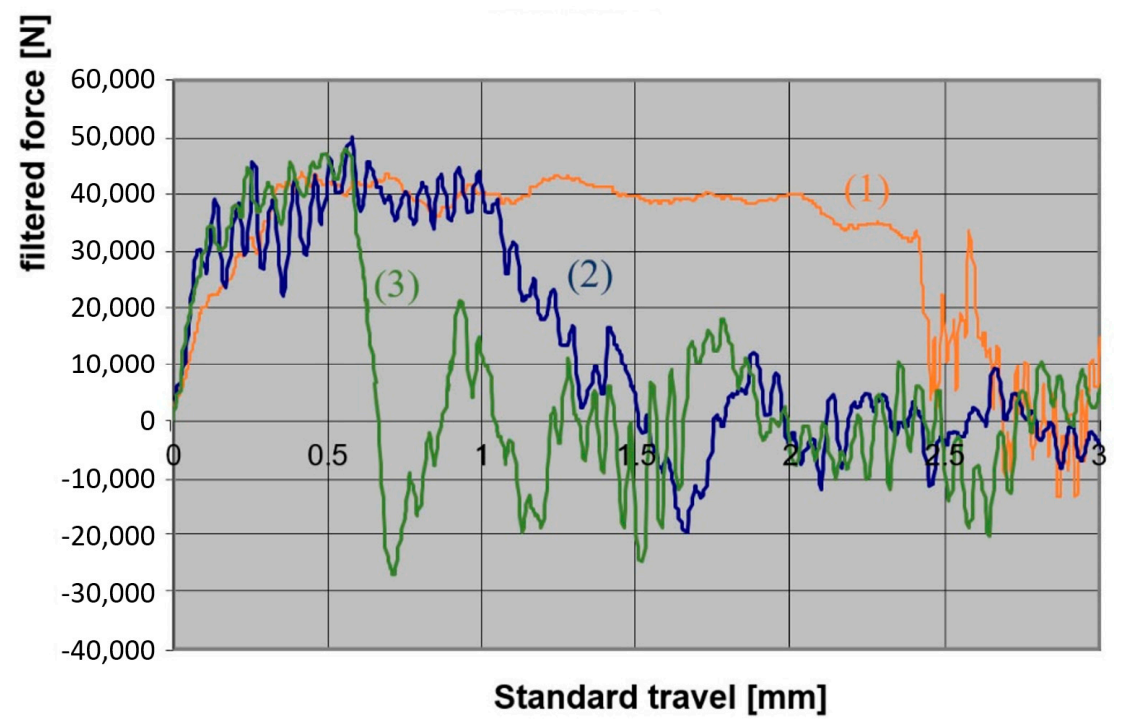

Figure 13. Typical fracture response at different loading rate ((1): $0.02 \mathrm{~m} / \mathrm{s},(\mathbf{2}): 3.48 \mathrm{~m} / \mathrm{s},(\mathbf{3}): 5.28 \mathrm{~m} / \mathrm{s})$.

\section{Conclusions}

The comparative experimental analyses revealed the specifics of fracture behavior in the Strenx 700MC steel. The fracture toughness, determined by CCRB samples under the static loading conditions, proved the higher values for the Strenx 700MC steel as compared to the S355NJ steel. The opposite ratio was observed when increasing the loading rate. The surprisingly lower dynamic fracture toughness of the Strenx 700MC steel compared to the S355NJ steel was observed despite the superiority of a brittle fracture mode in the S355NJ steel.

Increased fracture toughness due to an increased loading rate for both tested steels confirmed the decisive role of a plastic zone on top of the propagated crack. Intensive dynamic strengthening took 
place in the Strenx $700 \mathrm{MC}$ steel in the case of primary microstructure conditions as well as after the simulated degradation due to welding. The final dynamic fracture resistance of the temper-influenced zone even overcame the fracture resistance of the parent steel.

The critical sublayer of HAZ was defined as a maximal softening zone; the induced phase transformation and change of the structural components' morphology were evaluated in direct connection with the fracture response in this zone. Contrary to the common limited effect of the grain-coarsening zone adjacent to the fusion line, intensive reprecipitation was induced near the partial austenitisation zone.

The following advantages of the CCRB methodology have been confirmed:

- A uniaxial loading system as the optimal mode for monitoring all the circumstances of crack development;

- The ability to apply different loading rates, e.g., using the standard Charpy hammer system up to $5.23 \mathrm{~m} / \mathrm{s}$;

- Suppression of the plane stress state, typically influencing the crack propagation near the surface of the simple notched Charpy-type samples;

- Support for the plane orientation of the fracture due to the circumferential initiation of fatigue cracks.

The methodology used in this testing is especially effective for materials with heterogeneous microstructures and thereby with heterogeneous local mechanical parameters. Circumferential fatigue pre-cracking suppresses the fracture deflection towards weaker microvolumes and thus supports planar crack propagation. The CCRB methodology supports the plane strain condition; a transition of fracture to the main shear stress plane is suppressed significantly compared to Charpy-type samples.

Author Contributions: Conceptualization, E.S. and B.C.; Methodology, E.S., F.B. and B.C.; Investigation, E.S., F.B., S.K., M.U. and L.K.; Resources, E.S., and F.B.; Data curation, E.S., F.B. and S.K.; Writing-original draft preparation, E.S. and F.B.; Writing - review and editing, E.S. and F.B.; Visualization, E.S. and F.B.

Funding: This research was funded by the Railway Vehicle Competence Centre, project No.TE01020038.

Conflicts of Interest: The authors declare no conflict of interest.

\section{References}

1. Ulewicz, R.; Mazur, M.; Bokůvka, O. Structure and mechanical properties of fine-grained steels. Periodica Polytech. Transp. Eng. 2013, 41, 111-115. [CrossRef]

2. Mazur, M. Fatigue properties of fine-grained steels applied in components of semitrailers. Czasopismo Techniczne 2016, 4-M, 9-14.

3. Sperle, J.; Hallberg, L.; Larsson, J.; Groth, H. The Environmental Value of High Strength Steel Structures, Environmental Research Programme for the Swedish Steel Industry, The Steel Eco-Cycle; Scientific Report; Jernkontoret: Stockholm, Sweden, 2013; pp. 151-171.

4. Ulewicz, R.; Szataniak, P. Fatigue Cracks of Strenx Steel. Mater. Today Proc. 2016, 3, 1195-1198. [CrossRef]

5. Eckerlid1, J.; Åsell1, M.; Ohlsson1, A. Use of Vanadium High-Strength Low-Alloy Steels in Trailers, in a Case Study; The Steel Company Tunnplåt AB: Lulea, Sweden, 2009.

6. Laitila, J.; Larkiola, J.; Porter, D. Effect of forced cooling on the tensile properties and impact toughness of the coarse-grained heat-affected zone of a high-strength structural steel. Weld. World 2018, 62, 79-85. [CrossRef]

7. Kim, S.; Kang, D.; Kim, T.W.; Lee, J.; Lee, C. Fatigue crack growth behavior of the simulated HAZ of $800 \mathrm{MPa}$ grade high-performance steel. Mater. Sci. Eng. A 2011, 528, 2331-2338. [CrossRef]

8. Mohyla, P.; Hlavatý, I.; Tomčík, P. Cause of Secondary Hardening in Cr-Mo-V Weld during Long-Term Heat Exposure. Avtomaticheskaya Svarka 2011, 694, 24-26.

9. Górka, J. Influence of the maximum temperature of the thermal cycle on the properties and structure of the HAZ of steel S700MC. IOSR J. Eng. 2013, 3, 22-28. [CrossRef]

10. Górka, J.; Stano, S. Microstructure and Properties of Hybrid Laser Arc Welded Joints (Laser Beam-MAG) in Thermo-Mechanical Control Processed S700MC Steel. Metals 2018, 8, 132. [CrossRef] 
11. Shi, Y.; Han, Z. Effect of weld thermal cycle on microstructure and fracture toughness of simulated heat-affected zone for a 800 MPa grade high strength low alloy steel. J. Mater. Proc. Technol. 2008, 207, 30-39. [CrossRef]

12. Zhu, X.K.; Joyce, J.A. Review of fracture toughness (G, K, J, CTOD, CTOA) testing and standardization. Eng. Fract. Mech. 2012, 85, 1-46. [CrossRef]

13. Li, S.; He, J.; Gu, B.; Zeng, D.; Xia, Z.C.; Zhao, Y.; Lin, Z. Anisotropic fracture of advanced high strength steel sheets: Experiment and theory. Int. J. Plast. 2018, 103, 95-118. [CrossRef]

14. Leskov, V. Multi-Functional Kic-Test Specimen for the Assessment of Different Tool- and High-Speed-Steel Properties. Mater. Technol. 2013, 47, 273-283.

15. Grant, T.J.; Weber, L.; Mortensen, A. Plasticity in Chevron-notch fracture toughness testing. Eng. Fract. Mech. 2000, 67, 263-276. [CrossRef]

16. Antolovich, S.D.; Saxena, A.; Gerberich, W.W. Fracture mechanics-An interpretive technical history. Mech. Res. Commun. 2018, 91, 46-86. [CrossRef]

17. ASTM-E-399 Standard Test Method for Plane-Strain Fracture Toughness of Metallic Materials. E 399-90. 2003. Available online: https://www.astm.org/Standards/E399 (accessed on 27 April 2019).

18. Bayram, A.; Uguz, A.; Durmus, A. Rapid determination of the fracture toughness of metallic materials using circumferentially notched bars. J. Mater. Eng. Perform. 2002, 11, 571-576. [CrossRef]

19. Londe, N.V.; Jayaraju, T.; Rao, P.R.S. Determination of Plane-Strain Fracture Toughness of AL 2014-T6 Alloy Using Circumferentially Cracked Round Bar Specimen. Eng. E-Trans. 2006, 6, 26-31.

20. Wilson, C.D.; Landes, J.D. Fracture toughness testing with notched round bars. In Fatigue Fracture Mechanics: 30th Volume; ASTM International: West Conshohocken, PA, USA, 2000; pp. 69-82.

21. Londe, N.V.; Jayaraju, T.; Naik, P.; Kumar, D.; Rajashekar, C.R. Determination of fracture toughness and fatigue crack growth rate using circumferentially cracked round bar specimens of Al2014T651. Aerosp. Sci. Technol. 2015, 47, 92-97.

22. Li, D.M.; Bakker, A. Fracture toughness evaluation using circumferentially-cracked cylindrical bar specimens. Eng. Fract. Mech. 1997, 57, 1-11. [CrossRef]

23. Kuruppu, M.D.; Chong, K.P. Fracture toughness testing of brittle materials using semi-circular bend (SCB) specimen. Eng. Fract. Mech. 2012, 91, 133-150. [CrossRef]

24. Barsom, J.M.; Rolfe, S.T. Fracture and Fatigue Control in Structure: Applications of Fracture Mechanics, 2nd ed.; Prentice Hall: Englewood Clifts, NJ, USA, 1987.

25. ISO 26843:2015(E), Metallic Materials-Measurement of Fracture Toughness at Impact Loading Rates Using Precracked Charpy-Type Test Pieces. Available online: https://www.iso.org/standard/65516.html (accessed on 27 April 2019).

26. ASTM Designation E1820 - 17a, Standard Test Method for Measurement of Fracture Toughness. 2018. Available online: https://www.astm.org/Standards/E1820 (accessed on 27 April 2019). 